\title{
Relationship between Indoor Nicotine Concentrations, Time-Activity Data, and Urine Cotinine-Creatinine Ratios in Evaluating Children's Exposure to Environmental Tobacco Smoke
}

\author{
CHANG-CHUAN CHAN \\ SHU-CHING CHEN \\ JUNG-DER WANG \\ National Taiwan University \\ College of Public Health \\ Institute of Occupational Medicine and Industrial \\ Hygiene \\ Taipei, Taiwan
}

\begin{abstract}
The relationship among the three most frequently used environmental tobacco smoke measuring techniques was examined in this study: (1) indoor nicotine concentrations, (2) time-activity data, and (3) urine cotinine levels. Three families that included members who smoked and one family whose members did not smoke were selected from central Taiwan to participate in the study. The children's urine cotinine-creatinine ratios and the nicotine concentrations in the living rooms varied significantly between smokers' and nonsmokers' families. The multiple linear regression model indicated that both a child's cotinine-creatinine ratio, established by daily first-urine samples, and the day-averaged urine samples correlated well with the daily butt counts multiplied by the number of hours spent in the living room. It was concluded that daily first urine cotinine-creatinine ratios, as well as day-averaged urine cotinine-creatinine ratios, can predict the environmental tobacco smoke exposure of the previous day.
\end{abstract}

DESPITE THE FACT that health effects of environmental tobacco smoke (ETS) have been well documented in many studies, these investigations have mainly been conducted in Western countries.1,2 Public health problems associated with cigarette consumption in developing and newly developed countries might be more serious because the rate of smoking in these countries has continued to increase. Perhaps the increase in smoking in Taiwan results from the rapid economic growth and from the increased presence of foreign tobacco companies in Taiwan, where the importation of foreign cigarettes was legalized in January 1987. The tobacco consumption rate in the general population increased from $28.21 \%$ in 1986 to $32.5 \%$ in $1990 .^{3}$ The smoking rate among students in junior high school also increased from $12.3 \%$ in 1986 to $15.6 \%$ in 1991 , and among students in high school, the rate of smoking has increased from $13.8 \%$ to $17.6 \%$ for the same time period. ${ }^{4}$ The successful marketing of imported cigarettes can be best demonstrated by the preference of teen smokers. The results of a survey conducted in September 1987, 9 mo following the legalization of importation of foreign cigarettes, indicated that teen smokers preferred imported brands of cigarettes $(82.6 \%)$ over domestic brands $(10.6 \%) .^{5}$

Given such a trend in cigarette consumption, both active and passive smoking are expected to be serious public health problems in Taiwan. In this study, the authors investigated the feasibility of using simple exposure indicators of ETS-such as questionnaires, butt 
counts, air nicotine concentrations, and urine cotinine levels-to evaluate the exposure of children to passive smoking. Suitable indicators of ETS exposure were applied to assess the future public health impact of passive smoking in Taiwan.

\section{Method}

Three families with smoking members and one family with no smoking members were selected from central Taiwan to participate in the study. The housing situations for the four families were similar, except that the living room of one family (family 1 ) was approximately twice as large as the living rooms occupied by the remaining families. The natural ventilation of these homes was usually very good because there were front and back doors, as well as windows on the other two sides of the houses; no air conditioning was used. In response to the warm weather during the study period, the doors and windows were always kept open during the day hours. During night hours, windows remained open but the doors were shut. Meteorological data were obtained from a proximal observation station that was operated by the Taiwan National Meteorological Bureau. During the sampling period, the climatic conditions (expressed as mean \pm standard deviation $[S D]$ ) were as follows: temperature, $28.4 \pm 0.5{ }^{\circ} \mathrm{C}$; relative humidity, $83 \pm 3 \%$; atmospheric pressure, $1011 \pm 13$ $\mathrm{mg}$; and wind speed, $2.2 \pm 0.5 \mathrm{~m} / \mathrm{s}$. During the first 4 sampling $d$, there were thunderstorms in the afternoons.

Two evaluation methods were employed to characterize the impact of ETS on the quality of indoor air in the homes. The first method entailed measuring nicotine concentrations inside the participants' homes. In the living room of each house, a location where most of the smoking occurred, nicotine concentrations were measured continuously for $1 \mathrm{wk}$. In each home, three 24-h integrated nicotine concentration samples were measured, and two 48-h integrated nicotine concentration samples were measured for the remaining $4 \mathrm{~d}$ of the wk. Each air sample was usually obtained during a 24-h time period that commenced at 7 A.M. The inlet of each air sampler was located at a height of $1.2 \mathrm{~m}$ in the center of the living room. The air sampler assembly was equipped with a 37-mm PVC filter (SKC, Inc., pore size $=5 \mu$ ) that was placed in front of a sodium bisulfatetreated glass-fiber filter. An aluminum cyclone was connected to the filter assembly to allow particulates smaller than $5 \mu$ to pass the inlet at an air flow rate of 1.9 $\mathrm{I} / \mathrm{min}$ (SKC, Inc., Model 224-PCXR-7). At the conclusion of sampling, nicotine was extracted by ammoniated heptane and was analyzed by a gas chromatograph equipped with a nitrogen-phosphor-selective detector. The exaction rate of nicotine was about $85 \%$. The second evaluation method entailed collecting all cigarette butts that the participants had smoked and had subsequently placed in a special can in the living room during a 1 -wk period.

The four families in the study included nine male children who were 5-14 y of age. Two assessment methods were used to estimate ETS exposures of the children. The first was a time-activity survey that was conducted individually for all nine children. A timeactivity data sheet contained information about each individual's activities during a given day and the duration of exposure to ETS in various indoor and outdoor microenvironments. Activities were recorded for at least 30-min intervals. The data sheets were filled out by the children, except for two preschool children for whom sheets were completed by their mothers. The second method used to evaluate a child's ETS exposure was to determine the cotinine/creatinine ratio (CCR) in the child's urine. In an attempt to detect temporal variations in ETS exposures, an effort was made to collect and analyze every single micturition of urine from nine children during the entire study week. Urine cotinine was quantified by an enzyme-linked immunosorbent assay (ELISA) method (detection limit $=10 \mathrm{ng} / \mathrm{ml}$ ), using a commercially available polyclonal antibody (Serex, Inc.) ${ }^{6}$ Each individual urine sample was analyzed six times to ensure that a reliable ELISA measurement was obtained, and the average measurement errors from the six analyses were found to be within $10 \%$ for all urine samples. After collection, the urine samples were immediately stored at $-20^{\circ} \mathrm{C}$ until time of analysis to prevent deterioration of cotinine.

Urinary creatinine was also measured to adjust for variations in urine concentration, and the calculated CCR served as an ETS exposure indicator (see discussion). A research assistant was assigned to live in each participant's home during the period of study, thus ensuring quality control of air monitoring, urine collection, butt counts, and time-activity data. The completeness and reliability of data collection were principally assured by the observational and recording activities of these research assistants. Moreover, the three principal investigators were also in the field to verify the daily time-activity data. In addition, three children simultaneously recorded their activity patterns with the research assistants for $1 \mathrm{~d}$ to verify the validity of their recordings. The results indicated that the children's records of time, place, and ETS exposure probability were all relatively comparable with the records of the research assistants.

\section{Results}

Characteristics of the children were very similar for all four families (Table 1). Each family included two to three children, ages for whom ranged from 5 to $14 \mathrm{y}$. The cigarette butt counts in the living rooms of the three families that smoked were 30,36 , and 117 , respectively; of these, most were generated from the sole smokers, i.e., the fathers. No cigarette butts were found in the home of the nonsmokers.

As expected, children from homes with smoking members were more likely to be exposed to ETS than were children from the home in which no members smoked. The average number of times a child was with a smoker in the same location in the home was 23 for the seven children whose family member(s) smoked; this number decreased to 4 per child for the two chil- 
dren who lived in the home in which no member smoked. The percentage of time during which the children were exposed to active smokers at various indoor and outdoor locations also differed significantly between children from smoking and nonsmoking families. During times when children in smoking families were in their living rooms, dining rooms, or yards, approximately $14 \%-16 \%$ of the time they were exposed to active smokers. In contrast, the children from the nonsmoking family had virtually no exposure to active smokers while at these locations. There was, however, a high probability that all children were exposed to active smokers while at the video game shops: $50 \%$ for the children from families who smoked and $38.5 \%$ for the children from the nonsmoking family. Obviously, the main source of ETS exposure for children from the nonsmoking family was found at video game shops, rather than in their home. Sources of ETS exposure for the smokers' children were from indoor and outdoor microenvironments (Table 2).

Five measurements of air nicotine concentrations in each living room were conducted during the week. If measurements of nicotine concentrations were less than the limit of detection (LOD), one-half of the LOD was used in the calculation. Nicotine concentrations in the living rooms of the three smokers (mean $\pm S D: 0.80 \pm$
$0.62 \mu \mathrm{g} / \mathrm{m}^{3}$ ) were about 10 times the concentration found in the nonsmokers' living room $(0.07 \pm 0.08$ $\mu \mathrm{g} / \mathrm{m}^{3}$ ). During the week, a total of 243 urine samples were collected from the nine children: 58 samples were reflective of the first urine micturated of the day, 184 were from smokers' families, and 59 were obtained from the family members of the nonsmoking family. Among the samples, $52 \%$ were cotinine-positive and $48 \%$ were cotinine-negative for smokers' families; in contrast, $8 \%$ and $92 \%$ were cotinine-positive and cotinine-negative, respectively, in the family of nonsmokers. The CCRs for the children in smokers' families (4.13 $\pm 0.62 \mathrm{ng} / \mathrm{mg}$ ) were about 4 times higher than those found for children in the family of nonsmokers (1.16 \pm $0.72 \mathrm{ng} / \mathrm{mg}$ ) (Table 3).

General linear regression models from the SAS statistical package were applied to predict a child's urine CCR (in $\mathrm{ng} / \mathrm{mg}$ ) from the nicotine concentrations $\left(\mu \mathrm{g} / \mathrm{m}^{3}\right)$, butt counts, and time-activity data. ${ }^{7}$ The CCRs of both the daily first-urine sample and the day-averaged urine samples were used as ETS exposure indicators in these models. The best regression line for the relationship between the day-averaged CCR (CCR_D) and nicotine concentrations in the living room (nicotine_L) during the previous day is CCR_D $=1.02+2.79$ nicotine_L $\left(r^{2}=.60, n=52\right)$. With respect to the relation-

Table 1.-Characteristics of Four Families Who Participated in Environmental Tobacco Smoke (ETS) Exposure Study in Taiwan (1991)

\begin{tabular}{lccccc}
\hline \hline Family no. & $\begin{array}{c}\text { ETS source } \\
\text { at home }\end{array}$ & $\begin{array}{c}\text { Children } \\
\text { (no./family) }\end{array}$ & $\begin{array}{c}\text { Age } \\
(\mathrm{y})\end{array}$ & $\begin{array}{c}\text { Butt count } \\
\text { (no./wk) }\end{array}$ & $\begin{array}{c}\text { Living room } \\
\text { volume }\left(\mathbf{m}^{3}\right)\end{array}$ \\
\hline 1 & Father & 3 & $8,11,14$ & 117 & 99 \\
2 & Father & 2 & 9,13 & 30 & 64 \\
3 & Father & 2 & 5,6 & 36 & 44 \\
4 & None & 2 & 8,9 & 0 & 44 \\
\hline
\end{tabular}

Table 2.-Comparison of Time-Activity Patterns and Probability of ETS Exposure between Children from Homes of Smokers and Nonsmokers During 1 Wk

\begin{tabular}{|c|c|c|c|c|c|c|}
\hline \multirow[b]{3}{*}{ Location } & \multicolumn{4}{|c|}{ Time spent in microenvironments } & \multicolumn{2}{|c|}{ ETS exposure probability* } \\
\hline & \multicolumn{2}{|c|}{$\begin{array}{c}\text { Children }(n=7) \\
\text { of smokers }\end{array}$} & \multicolumn{2}{|c|}{$\begin{array}{l}\text { Children }(n=2) \\
\text { of nonsmokers }\end{array}$} & \multirow{2}{*}{$\begin{array}{c}\text { Children }(n=7) \\
\text { of smokers } \\
\%\end{array}$} & \multirow{2}{*}{$\begin{array}{c}\text { Children }(n=2) \\
\text { of nonsmokers } \\
\%\end{array}$} \\
\hline & $\mathrm{hr}$ & $\%$ & $\mathrm{hr}$ & $\%$ & & \\
\hline Living room & 251.0 & 21.3 & 109.0 & 32.3 & 16.1 & 0.0 \\
\hline Dining room & 23.5 & 2.0 & 0.5 & 0.2 & 14.9 & 0.0 \\
\hline Yard & 63.5 & 5.4 & 0.5 & 0.2 & 14.2 & 0.0 \\
\hline Child's bedroom & 577.0 & 49.1 & 173.5 & 51.6 & 0.7 & 0.0 \\
\hline Video game room & 1.0 & 0.1 & 6.5 & 1.9 & 50.0 & 38.5 \\
\hline Street vender & 1.5 & 0.1 & 0.5 & 0.2 & 33.3 & 0.0 \\
\hline Curbside & 68.5 & 5.8 & 12.0 & 3.6 & 5.1 & 4.2 \\
\hline Other & 190.0 & 16.2 & 33.5 & 10.0 & 1.3 & 0.0 \\
\hline Total & 1176.0 & & 336.0 & & & \\
\hline
\end{tabular}

*ETS exposure probability $=\mathrm{hr}$ when smokers around/total $\mathrm{hr}$ spent in the location. 
Table 3.-Comparison of Children's Urine Cotinine/Creatinine Ratios (CCRs) and Air Nicotine Concentrations in Living Room, between the Families Who Smoked and the Nonsmoking Family

\begin{tabular}{|c|c|c|c|c|c|}
\hline \multirow[b]{2}{*}{ ETS source at home } & \multirow[b]{2}{*}{ No. of persons } & \multicolumn{2}{|c|}{ CCR (ng/mg) } & \multicolumn{2}{|c|}{ Nicotine concentration $\left(\mu \mathrm{g} / \mathrm{m}^{3}\right)$} \\
\hline & & $\bar{x} \pm S D$ & Range (median) & $\bar{x} \pm S D$ & Range (median) \\
\hline Yes & 7 & $\begin{array}{c}4.29 \pm 3.66 \\
{[n=184]}\end{array}$ & $\begin{array}{c}\text { ND-26.0 }(3.55) \\
{[n=184]}\end{array}$ & $\begin{array}{c}0.80 \pm 0.62 \\
{[n=15]}\end{array}$ & $\begin{array}{c}\text { ND-2.15 (0.80) } \\
\quad[n=15]\end{array}$ \\
\hline No & 2 & $\begin{array}{c}1.17 \pm 0.71 \\
{[n=59]}\end{array}$ & $\begin{array}{c}\text { ND-3.10(1.00) } \\
{[n=59]}\end{array}$ & $\begin{array}{c}0.07 \pm 0.08 \\
{[n=5]}\end{array}$ & $\begin{array}{c}\text { ND-0.21 (0.06) } \\
\quad[n=5]\end{array}$ \\
\hline
\end{tabular}

ship between CCRs of the daily first urine sample (CCR_F) and nicotine concentrations in the living room during the previous day, the best regression line is $C C R \_F=1.11+2.98$ nicotine_L $\left(r^{2}=.52, n=48\right)$. The predicted values of the CCRs, however, were not improved by adding another variable-size of living room-to these regression models. A similar correlation was also found between an individual's CCR and daily butt counts multiplied by the numbers of hours spent in the living room. In the linear regression models, such a correlation was approximately the same for the CCRs for both the whole-day-averaged urine samples $\left(r^{2}=\right.$ $.60, n=52, p=.0015$ ) and for the first-urine sample collected the following day $\left(r^{2}=.60, n=48, p=\right.$ .0267). This similarity indicated that a significant proportion of a child's ETS exposures occurred at the home during the night. The time-activity data also reflect that most ETS exposures occurred during the night when the children stayed with their fathers' at home. The similar $r^{2}$ values indicate an equivalent applicability of using the measurements of nicotine concentrations and the cigarette butt counts in the living rooms as ETS emission indicators.

\section{Discussion}

The monoclonal antibody-based ELISA method, developed by Langone et al., ${ }^{8}$ was used to determine CCRs and was found to have positive and negative prediction rates of $52 \%$ and $100 \%$, respectively. The ELISA method used in this study is based on commercially available polyclonal antibody and has a positive predictive rate of $58 \%$ and a negative predictive rate of $92 \%$. Although both methods are equally specific in determining the ETS exposure status of nonexposed children, these methods are insufficiently sensitive to determine the ETS in exposed children. The possibility of misclassification of ETS exposures was approximately $40 \%$ to $50 \%$ when we measured an exposed child's CCR in a single urine sample.

Urine CCR measurements of ETS-exposed children in our study were lower than values reported in other studies conducted in Western countries. ${ }^{9-11}$ Furthermore, in the current study nicotine concentrations found in living rooms were lower, compared with concentrations reported in studies performed in countries with temperate climates. ${ }^{12-14}$ The lower CCRs and lower nicotine concentrations are thought to result mainly from better ventilation of homes in our study. Despite the fact that the ventilation rate was not measured in our study, it was anticipated that the homes would have a very high ventilation rate during the hot and humid sampling period.

Questionnaires, including time-activity data, have long been thought to be a convenient, unintrusive, but less-accurate method of estimating ETS exposure. ${ }^{15}$ Our study confirmed that time-activity data alone were insufficient for estimating ETS exposure because there was no correlation between a child's urine CCR and the ETS exposure recorded on his time-activity data sheet during the previous day. We found, however, that a child's time spent in the living room multiplied by the butt counts in the same room for the previous day was a good predictor of his urine CCR on the following day. Apparently, a more objective way of documenting a child's ETS exposures can be achieved by counting cigarette butts, rather than by reporting only daily activities.

It appears that the least complicated way to estimate ETS exposure in population studies is to collect information on the time activities of individuals and to count the number of cigarette butts in their living rooms. More sophisticated approaches, such as measuring nicotine concentrations in living rooms and determination of CCRs from nonsmoker's daily first-urine sample, are recommended if finances permit.

Submitted for publication June 1, 1993; revised; accepted for publication June 6, 1994.

Requests for reprints should be sent to Chang-Chuan James Chan, National Taiwan University, College of Public Health, Institute of Occupational Medicine and Industrial Hygiene, Rm. 1447 No. 1, JenAi Road, 1st Sec., Taipei, Taiwan.

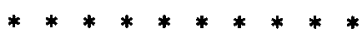

\section{References}

1. U.S. Department of Health and Human Services. The health consequences of involuntary smoking: a report of the SurgeonGeneral. DHHS[CDC] Publication no. 87-8398. Rockville, MD: U.S. Public Health Service, 1986.

2. National Research Council. Environmental tobacco smoke: measuring exposures and assessing health effects. Washington, D.C.: National Academy Press, 1986.

3. Taiwan Tobacco \& Wine Monopoly Bureau. Report on tobacco 
and wine consumption in Taiwan. Taipei, Taiwan: Taiwan Tobacco \& Wine Monopoly Bureau, 1991.

4. Report of China Department of Health. Special report on the world no tobacco day. Taipei, Taiwan: ROC Department of Health, 1991.

5. The John Tung's Foundation. Report on smoking among young in fast food restaurants in Taipei. Taipei, Taiwan: The John Tung's Foundation, 1987

6. Serex, Inc. Coti-Traq quantitative cotinine ELISA kit. Tenafly, NJ: Serex, Inc.

7. SAS Institute, Inc. SAS procedures guide. Cary, NC: SAS Institute, Inc., 1988; release 6.03 .

8. Langone JJ, Cook G, Bjercke RJ, Lifschitz MH. Monoclonal antibody ELISA for cotinine in saliva and urine of active and passive smokers. J Immunol Methods 1988; 14:73-78.

9. Ehrlich R, Kattan M, Godbold J, et al. Childhood asthma and passive smoking. Am Rev Respir Dis 1992; 145:594-99.

10. Coultas DB, Samet JM, McCarthy JF, Spengler JD. A personal monitoring study to assess workplace exposure to environmental tobacco smoke. Am J Public Health 1990; 80:988-90.

11. Wall MA, Johnson J, Jacob P, Benowitz NL. Cotinine in serum, saliva, and urine of nonsmokers, passive smokers, and active smokers. Am J Public Health 1988; 78:699-701.

12. Leaderer BP, Hammond SK. Evaluation of vapor-phase nicotine and respirable suspended particle mass as markers for environmental tobacco smoke. Environ Sci Technol 1991; 25:770-77.

13. Coultas DB, Samet JM, MCCarthy JF, Spengler JD. Variability of measures of exposure to environmental tobacco smoke in the home. Am Rev Respir Dis 1990; 142:602-06.

14. Henderson FW, Reid HF, Morris R. Home air nicotine levels and urine cotinine excretion in preschool children. Am Rev Respir Dis 1988; 140:197-201.

15. Coultas DB, Peake GT, Samet JM. Questionnaire assessment of lifetime and recent exposure to environmental tobacco smoke. Am J Epidemiol 1989; 130:338-347.

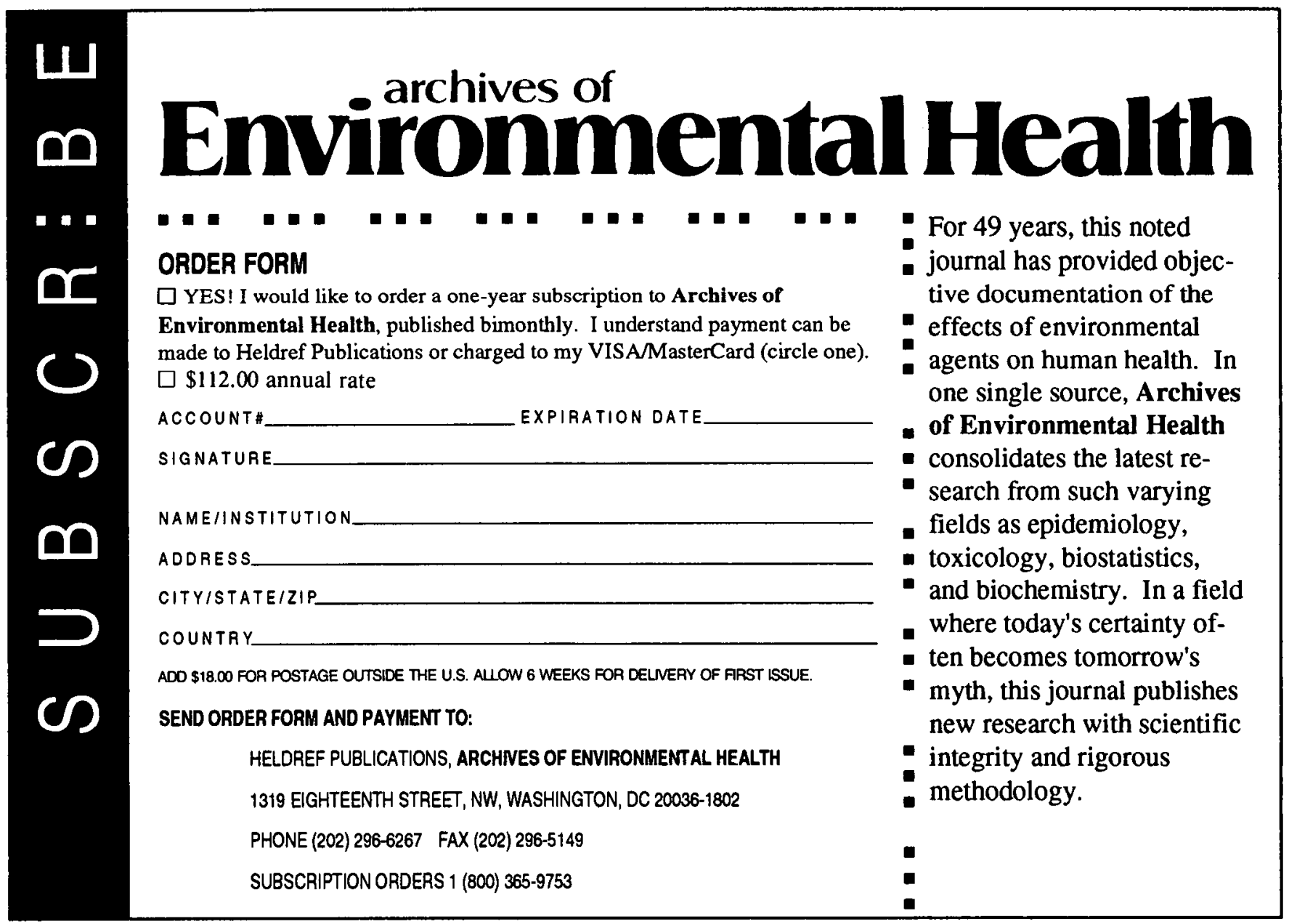


Copyright of Archives of Environmental Health is the property of Heldref Publications and its content may not be copied or emailed to multiple sites or posted to a listserv without the copyright holder's express written permission. However, users may print, download, or email articles for individual use. 